Seminar Nasional Teknologi Informasi dan Kedirgantaraan (SENATIK)

Vol. II, 26 November 2016, ISSN: 2528-1666

\title{
ANALISIS KEKUATAN STRUKTUR RETAK SKIN FUSELAGE REPAIR PESAWAT B747-400
}

\author{
Djarot Wahju Santoso ${ }^{1}$, Ari Wibowo ${ }^{2}$ \\ ${ }^{1,2}$ Sekolah Tinggi Teknologi Adisutjipto, Yogyakarta \\ Jl.Janti Blok R Lanud Adisutjipto, Yogyakarta \\ E-mail : djarot_wahyu84@yahoo.com
}

\begin{abstract}
Structure Repair Manual (SRM) is guidelines issued by manufactured to the the MRO (Maintenance and Repair Organization) to perform a repair aircraft. SRM function at an actual reference to make modification repair. In its application modifications can be done by changes use the layout variations and fastener.Determine the feasibility of a modifications repair configuration done by modeling and analysis that structure to determine the maximum stress that occurs in that configurations.

In this research, configuration model that SRM structure repair and modification of the structure repair SRM was created. Both models are given internal pressure load, while the fastener strength was tested by making a simpler model to provide tensile load. Both those structures model and analysis by software CATIA V5R21.

The maximum stress that occurs in structures modification SRMrepair is 18265 Psi by the internal pressure loading, whereas for tension loading cases a mounted 22380.9 Psi.Based on the margin of safety the modifications structure of SRM repair declared to be safer than SRM structure repair, so that the structure can be used as an alternative repair if the repair scame for SRM repair is not possible to do.
\end{abstract}

Keywords : skin fuselage, repair, crack, SRM

\section{Pendahuluan}

Structure Repair Manual (SRM) merupakan panduan repair yang dikeluarkan oleh manufacture kepada MRO (Maintenance and Repair Organization) atau yang mempunyai wewenang untuk melakukan perbaikan pesawat. Repair adalah usaha untuk memperbaiki sesuatu yang rusak agar tetap bisa digunakan, begitu pula dengan modifikasi yang dilakukan. Dalam aplikasinya modifikasi dapat dilakukan dengan merubah ataupun mengganti material repair dengan material alternatifyang lain. $S R M$ berfungsi sebagai acuan repair aktual dalam melakukan suatu modifikasi repair.

Repair yang terdapat dalam dokumen Boeing Structural Repair Manual hanya digunakan untuk menentukan durability dan damage tolerance. Designer dan analis Boeing hanya memiliki data fatigue load pada saat pertama kali pesawat dirancang dan ketika membuat SRM repair. Beban fatigue secara umum tidak diketahui oleh engineer develop repair, dengan alasan inilah konfigurasi repair yang muncul dalam SRM hanya merupakan landasan dari repair konfigurasi aktual yang diaplikasikan pada pesawat yang mengalami kerusakan.

Pada saat engineer dalam melakukan repair pesawat, di mana ada kemungkinan tidak bisa diaplikasikan dalam repair scame secara langsung seperti yang telah disajikan dalam SRM. Hal inilah yang mendasari dibolehkannya untuk melakukan modifikasi repair dari SRM yang dimaksud yang mencakup antara lain; variasi layout (konfigurasi pada local structure), dan variasi fastener yang digunakan.

Salah satu pendekatan yang disajikan disini adalah dengan melakukan analisis yang direkomendasikan dari $S R M$ melalui asumsi beban, dengan menggunakan beban tersebut dan pendekatan untuk menganalisis konfigurasi repair yang telah direvisi. Pada penelitian ini penulis melakukan modifikasi SRM repair dari struktur Fuselage skin repair untuk mengetahui pengaruh 
perubahan jumlah fastenerterhadap kekuatan struktur tersebut.

\section{Tinjauan Pustaka}

Hasil analisis kekuatan struktur pada Single rivet lap joint dilakukan dengan metode Finite Element Analysis (FEA) dengan software ANSYS menunjukkan nilai tegangan geser maksimum di antara 138,44 MPa sampai 184,57 MPa, sedangkan untuk hasil perhitungan analitik sebesar 170,31 MPa [1].

Selanjutnya analisis kekuatan struktur Riveted Butt Joint dengan metode Finite Element Method (FEM) dan software ANSYS diperoleh nilai tegangan maksimum Von Mises diantara $90 \mathrm{MPa}$ sampai $188 \mathrm{MPa}$, sedangkan untuk hasil perhitungan analitik sebesar 180,49MPa, juga diperoleh metode pemasangan chain lebih aman dibandingkan dengan zig-zag [2].

Pada kedua penelitian tersebut di atas struktur hanya melibatkan skin dan rivet, sedangkan pada penelitian ini selain kedua struktur tersebut model juga ditambahkan struktur stringer dan frame serta melibatkan doubler untuk memperkuat struktur repairnya.

\subsection{Fuselage Skin}

Fuselage skin merupakan salah satu bagian struktur terluar dari struktur fuselage (airframe). Struktur skin pada fuselage terhubung dengan stringer dan shear tie yang menjadi satu pada circumferential frame yang dihubungkan oleh fastener. Shear tie merupakan suatu plate yang menjadi satu kesatuan pada struktur frame. Shear tie dirancang untuk mentranfer bebaninternal dari skin fuselage ke frame atau sebaliknya untuk mempertahankan bentuk dari skin fuselage [3].

Dalam aplikasinya fuselage mengalami pembebanan yang sangat komplek, salah satunya yaitu pembebanan karena adanya perbedaan tekanan (differential internal pressurization). Fuselage skin akan mengalami pressurized atau depressurized pada setiap flight cycle saat take-off dan landing, hal inilah yang menyebabkan skin fuselage akan mengembang dan mengerut seiring berjalannya siklus.

Crack (retak) akan terjadi akibat perbedaan tekanan yang disebabkan oleh tegangan geser pada struktur skin fuselage (fuselage shear load).
Tegangan yang terjadi pada arah circumferential (hoop stress) menyebabkan adanya konsentrasi tegangan pada lubang-lubang fastener, di mana lokasi ini menjadi lokasi tegangan yang cukup tinggi dan merupakan titik lokasi potensial initial crack. Retak awal yang terjadi pada lubang fastener semakin lama akan semakin bertambah lebar sehingga membentuk retak yang panjang pada arah longitudinal fuselage skin [4].

\subsection{Beban Pada Struktur Skin Fuselage}

Ada 2 beban yang terjadi pada skin fuselage yaitu cabinpressure dan fuselage shear load.

\section{a. Cabin pressure /Internal Load}

Cabin Pressuremerupakan beban yang bekerja pada skinfuselage yang besarnya tergantung pada kondisi ketinggian jelajah dan tingkat kenyamanan yang diinginkan. Prinsip pressurize cabin pada pesawat terbang komersialdirancang untuk menjaga cabin pesawat tetap nyamanselama penerbangan. Perbedaan tekanan juga dapat ditentukan dari grafik ketinggian (altitude chart) [4,5].

Tekanan cabin pesawat terbang komersial secara umum, dirancang pada ketinggian $8.000 \mathrm{ft}$ saat mengaplikasikan pressurize cabin.

Untuk menentukan beda tekanan $(\Delta \mathrm{P})$ dapat diperoleh dari Diagram Nomogram pada Gambar 1.

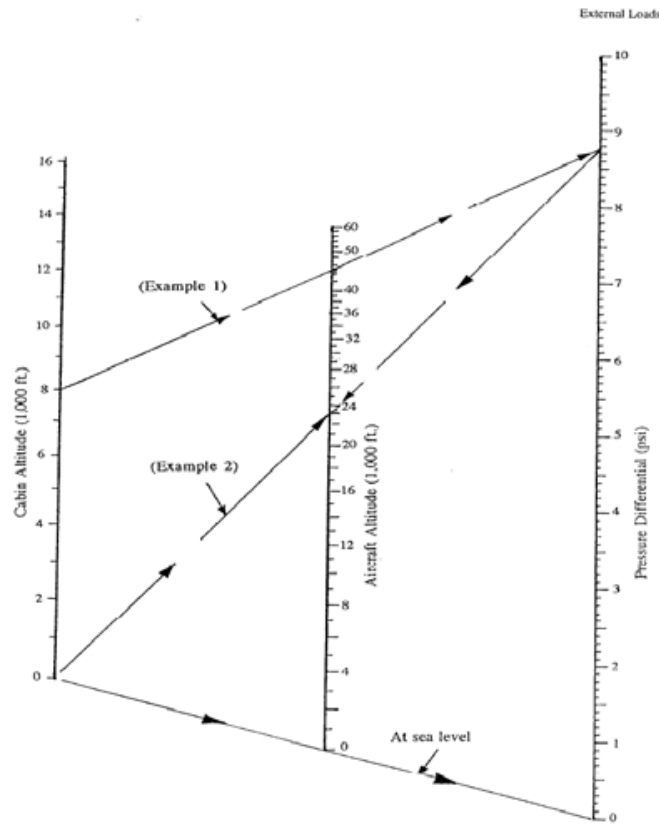

Gambar 1 Diagram Nomogram 


\section{b. Fuselage shear load}

Beban geser fuselage pada skin fuselage adalah besarnya tegangan geser yang terjadi pada sheet (plate) yang disebabkan beban tarik. Untuk mengetahui besar pembebanannya menggunakan prinsip dari running load. Running load adalah jenis beban yang terjadi pada web maupun skin setelah dikenakan gaya, dengan running loadmerupakan gaya per unit panjang (lb/in).

Beban geser fuselage disebabkan adanya perbedaan tekanan di dalam dan diluar passenger cabin $(\Delta \mathrm{P})$ yang menghasilkan beban tarik arah axial dan radial.Prinsip pressure vessel dalam membrane atau hoop merupakan teganganyang terjadipada fuselage skin dan curve bulkhead. Gambar 2 merupakan ilustrasi pengaruh dari perbedaan tekanan $(\Delta \mathrm{P})$ pada skin fuselage. Tegangan terbagi menjadi dua yaitu arah circumferential $\left(\mathrm{f}_{\text {hoop }}\right)$ dan arah longudinal $\left(\mathrm{f}_{\text {lonoitudinal }}\right)$ yang dapat dilihat pada persamaan 1 dan 2 [4]:

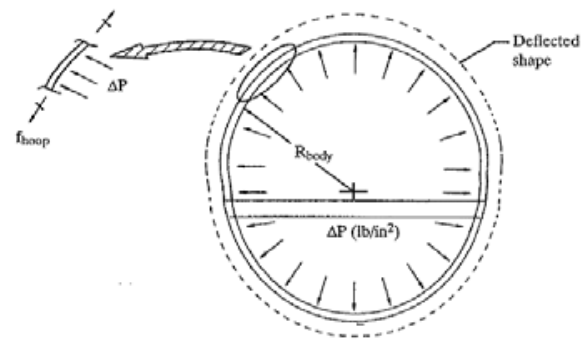

Gambar 2. Ilustrasi pengaruh perbedaan tekanan pada skin fuselage

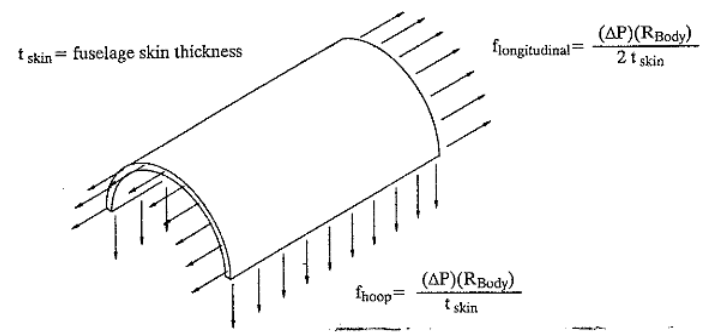

Gambar 3 Resultan stress dari pressure load pada fuselage skin

Persamaan untuk tegangan longitudinal adalah :

$$
\mathrm{f}_{\text {longitudinal }}=\frac{(\Delta \mathrm{P}) \cdot\left(R_{\text {Body }}\right)}{2 \cdot t_{\text {skin }}}
$$

Berdasarkan persamaan (1) persamaan untuk running load longitudinal tension adalah:

$$
\mathrm{w}_{\text {longitudinal }}=\frac{(\Delta \mathrm{P}) \cdot\left(R_{\text {Body }}\right)}{2}
$$

Sedangkan untuk persamaan tegangan hoop adalah :

$$
\mathrm{f}_{\text {hoop }}=\frac{(\Delta \mathrm{P}) \cdot\left(R_{\text {Body }}\right)}{t_{\text {skin }}}
$$

Berdasarkan persamaan (3) persamaan untuk running load hoop tension yaitu :

$$
\begin{aligned}
& \mathrm{W}_{\text {hoop }}=(\Delta \mathrm{P}) \cdot\left(R_{\text {Body }}\right) \\
& \text { Dimana: } \\
& \Delta \mathrm{P} \quad=\text { Parameter of pressure }(P s i) \\
& \mathrm{R}_{\text {body }}=\text { Radius fuselage }(\text { in }) \\
& \mathrm{t}_{\text {skin }}=\text { Thickness fuselage skin }(\text { in })
\end{aligned}
$$

\subsection{Kekuatan Struktur}

Pada dasarnya komponen struktur pesawat terbang dirancang sedemikian rupa sehingga memiliki kekuatan struktur yang memadai untuk dapat menahan beban limit ataupun ultimate secara aman, tanpa terjadi kegagalan atau tanpa mencapai titik luluh dari material tersebut.

Pada sifat mekanik material tertentu beban luluh (yield load) dapat diasumsikan sebagai beban maksimum yang dapat diterima oleh suatu struktur sehingga mencapai kondisi kritis yang besarnya tergantung kepada material pembentuk struktur.

Salah satu metode yang digunakan untuk menentukan kekuatan struktur dalam pesawat adalah menggunakan perhitungan batas keamanan (margin of safety/MS). MS didefinisikan sebagai ukuran besarnya kemampuan atau kapasitas yang masih tersedia dalam suatu struktur untuk menerima beban statik secara aman pada kondisi pembebanannya.

Dalam bentuk tegangan persamaan $M S$ adalah :

Margin of Safety $(M S)=\frac{\sigma_{\text {all }}}{\sigma_{\text {app }}}-1 \geq 0$

Dimana:

$\begin{array}{ll}\sigma_{\text {all }} & : \text { Tegangan yang diijinkan } \\ \sigma_{\text {app }} & : \text { Tegangan yang diterapkan }\end{array}$

\section{Metode Penelitian}

Penelitian ini dilakukan dengan membuat 2 model struktur skin fuselage yang mengalami retak dengan mengambil sampel data pesawat Boeing 747-400 yang mengalami repair. Struktur tersebut 
terletak di Section 42, Body Station 680 pada stringer 23 sebelah kiri. Kedua model tersebut adalah:

(1) Struktur retak skin fuselage sesuai SRM.

(2) Struktur retak modifikasi skin fuselage berdasarkan Boeing Structural Repair for Engineer.

Kedua struktur tersebut dimodelkan dengan menggunakan software CATIA V5R21. Model pertama menggunakan panduan Repair 13 detail II untuk Station 540-980 Stringer 23 sesuai dengan SRM pesawat B747-400.

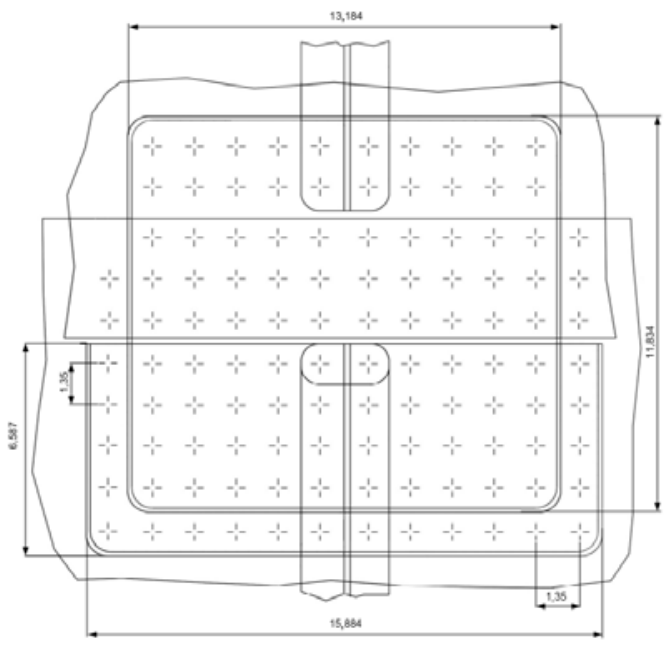

Gambar 4. Layout Model pertama

Model kedua dibuat dari model pertama dengan mengurangi 1 baris fastener pada arah circumferential, sehingga layout modifikasi SRM repair-nya seperti tercantum pada gambar 5 .

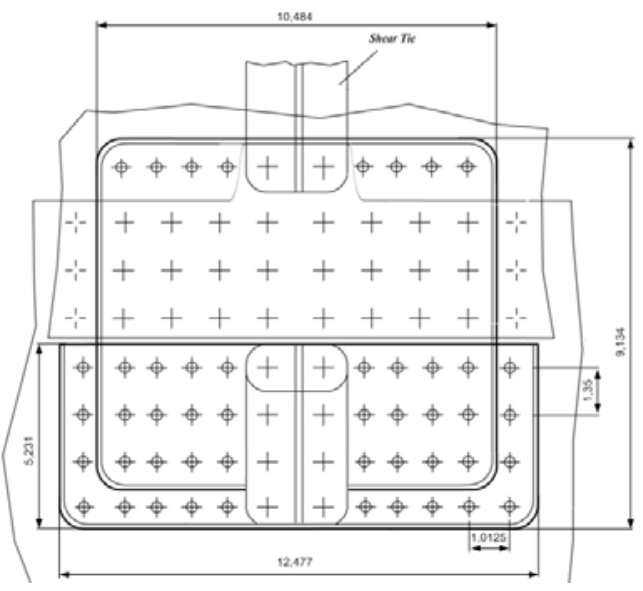

Gambar 5. Layout modifikasi model kedua
Langkah selanjutnya adalah memberikan beban internal pressure sebesar 9 Psi sesuai dengan ketinggian terbang pesawat Boeing 747-400. Beban tension juga diterapkan pada kedua model tetapi dengan model struktur yang lebih sederhana. Kemudian kedua model tersebut dilakukan analisis dengan software CATIA untuk mendapatkan tegangan maksimum.

Tegangan maksimum tersebut digunakan untuk menghitung Margin of Safety. Kedua model tersebut dibandingkan untuk untuk menentukan apakah struktur modifikasi masih aman digunakan untuk aplikasi di lapangan.

\section{Hasil Dan Pembahasan}

\subsection{Struktur Retak SRMrepair.}

Pada pembebanan internal pressure tegangan maksimum von mises sebesar 19268,00Psi terletak padafastener BACR15CE5D initial. Hal ini disebabkan pada struktur skin SRMrepair, part doubler mempunyai kekakuan yang lebih tinggi dibandingkan part lainnya. Beban pressure tersebut pada arah sumbu- $Z$ mengenai bagian dalam skin fuselage yang terdistribusi merata. Beban tersebut menyebabkan tegangan terpusat pada area skin yang berdekatan dengan clamp (frame dan stringer). Fastener sebagai pengikat antara skin dengan support (frame dan stringer) akan menerima beban yang lebih tinggi sebelum beban tersebut ditranfer ke struktur frame dan stringer.

Sedangkan besar nilai margin of safety pada tegangan maksimumnya adalah 0,661 dari perhitungan berikut :

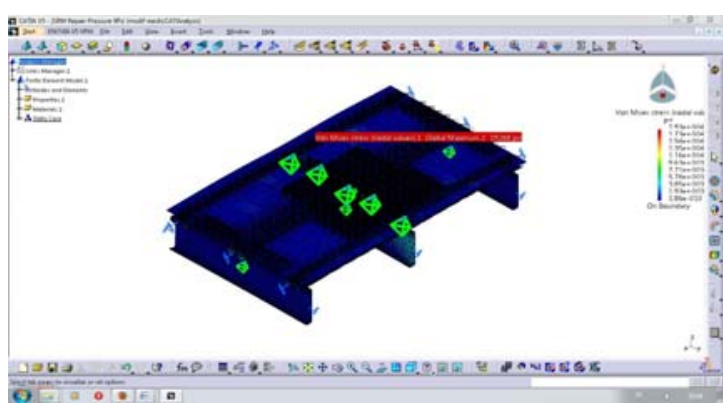

Gambar 6.Tegangan maksimum Von misses

Dari hasil analisis yang tercantum pada tabel 1 untuk jenis pembebanan internal pressure secara keseluruhan pada struktur retak skin fuse large repair SRM dinyatakan aman, dimana nilai $M S$-nya bernilai positif. 
Tabel 1. Data teganganmaksimum pada part

\begin{tabular}{|c|c|c|c|}
\hline Part & $\begin{array}{c}\text { Tegangan } \\
\text { Maksimum } \\
\text { (Psi) }\end{array}$ & $\begin{array}{c}\text { Yield } \\
\text { Strength } \\
\text { (Psi) }\end{array}$ & $\begin{array}{c}\text { Margin } \\
\text { of } \\
\text { Safety }\end{array}$ \\
\hline Frame 670 & 5563,68 & 65000 & 10,683 \\
\hline Frame 680 & 7366,13 & 65000 & 7,824 \\
\hline Frame 690 & 3832,10 & 65000 & 15,962 \\
\hline Stringer 22 & 4192,13 & 65000 & 14,505 \\
\hline Stringer 23 & 8434,64 & 65000 & 6,706 \\
\hline Stringer 24 & 4410,51 & 65000 & 13,738 \\
\hline Upper Skin & 2582,17 & 45000 & 16,427 \\
\hline Lower Skin & 3725,44 & 45000 & 11,079 \\
\hline Doubler & 3770,31 & 45000 & 10,935 \\
\hline Filler & 2821,19 & 45000 & 14,951 \\
\hline Filler $_{\text {(cut on }}$ & 1748,60 & 45000 & 24,735 \\
\hline BACR15CE5D ${ }^{\text {initial }}$ & 19268,00 & 32000 & 0,661 \\
\hline BACR15CE6D & 4300,64 & 32000 & 6,441 \\
\hline $\mathrm{BACR}^{2}$ 15B5D ${ }_{i}^{\text {nitial }}$ & 8911,57 & 32000 & 2,591 \\
\hline
\end{tabular}

Untuk mengetahui kekuatan fastener pada area skin repair, dilakukan pengujian beban tension dengan pemodelan struktur yang lebih sederhana. Model diclamp pada salah satu ujung potongan skin sedangkan ujung skin yang lain diberikan beban tension pada arah circumferentiall (sumbu Y).

Nilai tegangan maksimun von mises sebesar 23605,8Psi terletak pada fastener BACR15CE6D4 bagian terluar dari area skin repair. Sedangkan nilai $M S$-nya adalah 0,356 .

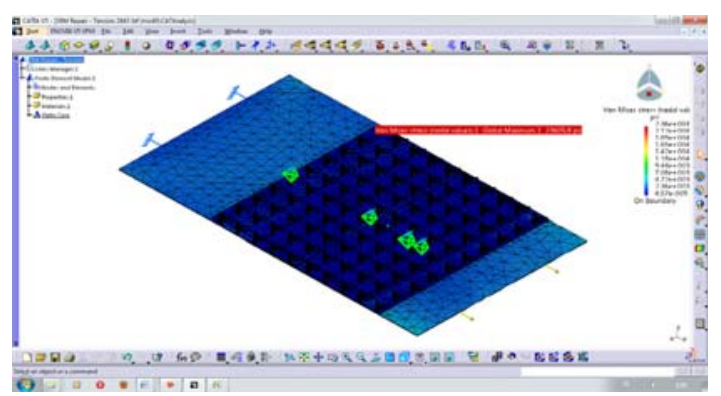

Gambar 7.Tegangan maksimum beban tension

Beban tension pada arah circumferential menyebabkan beban terdistribusi merata searah dengan arah gaya sumbu part. Begitu juga tegangan yang terjadi pada area skin repair doubler, akan menyebabkan tegangan maksimum pada bagian ujung (terluar) dari skin repairdoubler.

Fastener sebagai pengikat juga akan mentransfer beban yang terjadi pada skin-skin tersebut, sehingga fastener terluar dari skin repair (BACR15CE6D4) akan menerima beban yang lebih tinggi dibandingkan fastener bagian dalam pada skin repair doubler.

Tabel 2. Data tegangan maksimum pada part

\begin{tabular}{|l|c|c|c|}
\hline \multicolumn{1}{|c|}{ Part } & $\begin{array}{c}\text { Tegangan } \\
\text { maksimum } \\
\text { (Psi) }\end{array}$ & $\begin{array}{c}\text { Yield } \\
\text { Strength } \\
\text { (Psi) }\end{array}$ & $\begin{array}{c}\text { Margin } \\
\text { of Safety }\end{array}$ \\
\hline Upper Skin & 4184,21 & 45000 & 9,755 \\
\hline Lower Skin & 6150,67 & 45000 & 6,316 \\
\hline Doubler & 4412,16 & 45000 & 9,199 \\
\hline Filler & 6902,89 & 45000 & 5,519 \\
\hline Filler & & & \\
\hline $\begin{array}{l}\text { Fast out) } \\
\text { BACR15CE6D }\end{array}$ & 396,696 & 45000 & 112,437 \\
\hline $\begin{array}{l}\text { Fast } \\
\text { BACR15BB6D }\end{array}$ & 23605,8 & 32000 & 0,356 \\
\hline $\begin{array}{l}\text { Fast } \\
\text { BAC30NW6 }\end{array}$ & 1470,9 & 32000 & 20,755 \\
\hline
\end{tabular}

Dari hasil analisis yang tercantum pada tabel 2 untuk jenis pembebanan tension secara keseluruhan pada struktur retak skin fuse lager repair SRM dinyatakan aman.

\subsection{Struktur retak Modifikasi SRM repair.}

Dari pemodelan diperoleh nilai tegangan maksimum von mises sebesar 18265 Psi terletak pada fastener BACR15CE5D initial, hal ini juga tidak jauh berbeda dengan hasil pada model pertama. Sedangkan nilai $M S$ sebesar 0,752. Berdasarkan nilai $M S$ pada tabel 3 struktur retak skin fuselage repair modifikasi aman terhadap beban internal pressure.

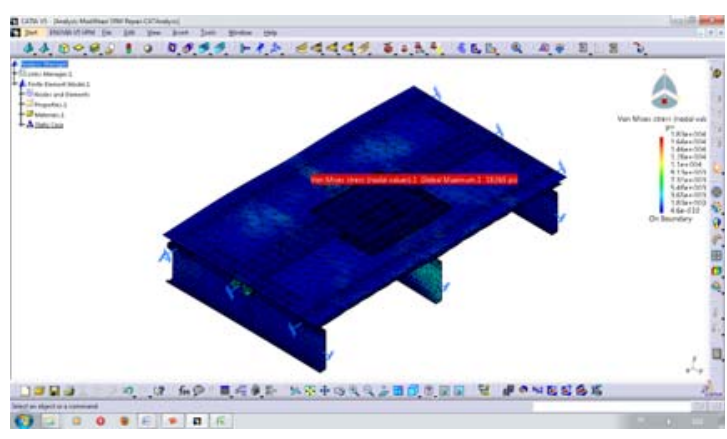

Gambar 8. Tegangan maksimum beban internal pressure 
Tabel 3.Data Tegangan maksimum

\begin{tabular}{|l|c|c|c|}
\hline \multicolumn{1}{|c|}{ Part } & $\begin{array}{c}\text { Tegangan } \\
\text { Maksimum } \\
\text { (Psi) }\end{array}$ & $\begin{array}{c}\text { Yield } \\
\text { Strength } \\
\text { (Psi) } \\
\text { Frame 670 }\end{array}$ & $\begin{array}{c}\text { Margin of } \\
\text { Safety }\end{array}$ \\
\hline Frame 680 & 3612,77 & 65000 & 16,992 \\
\hline Frame 690 & 7521,71 & 65000 & 7,642 \\
\hline Stringer 22 & 4070,46 & 65000 & 14,969 \\
\hline Stringer 23 & 7476,76 & 65000 & 7,694 \\
\hline Stringer 24 & 518,967 & 65000 & 124,249 \\
\hline Upper Skin & 3159,99 & 45000 & 13,241 \\
\hline Lower Skin & 4263 & 45000 & 9,556 \\
\hline Doubler & 8075,12 & 45000 & 4,573 \\
\hline Filler & 4225,81 & 45000 & 9,649 \\
\hline Filler ${ }_{\text {(cum out) }}$ & 1145,21 & 45000 & 38,294 \\
\hline $\begin{array}{l}\text { BACR15CEDD } \\
\text { initial }\end{array}$ & 18265 & 32000 & 0,752 \\
\hline BACR15CE6D & 5233,77 & 32000 & 5,114 \\
\hline
\end{tabular}

Sedangkan pada kasus beban tension tegangan maksimum von mises sebesar 22380,9Psi terletak pada fastener BACR15CE6D4 pada bagian terluar dari area skin repair.

Berdasarkan perhitungan Margin of Safety diperoleh nilai sebesar 0,430 sehingga dapat dikatakan bahwa fastener BACR15CE6D4 aman terhadap pembebanan tension.

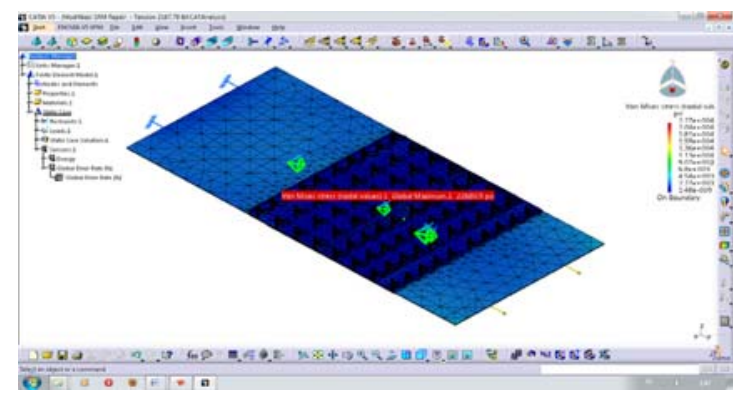

Gambar 9. Tegangan maksimum Von Misses pada beban tension

Tabel 4.Data Tegangan maksimum

\begin{tabular}{|l|c|c|c|}
\hline \multicolumn{1}{|c|}{ Part } & $\begin{array}{c}\text { Tegangan } \\
\text { Maksimum } \\
\text { (Psi) }\end{array}$ & $\begin{array}{c}\text { Yield } \\
\text { Strength } \\
\text { (Psi) }\end{array}$ & $\begin{array}{c}\text { Margin of } \\
\text { Safety }\end{array}$ \\
\hline Upper Skin & 4698,2 & 45000 & 8,578 \\
\hline Lower Skin & 5191,99 & 45000 & 7,667 \\
\hline Doubler & 3315,93 & 45000 & 12,571 \\
\hline Filler & 2985,78 & 45000 & 14,071 \\
\hline Filler $_{\text {(cut out) }}$ & 418,899 & 45000 & 106,424 \\
\hline
\end{tabular}

\begin{tabular}{|c|c|c|c|}
\hline $\begin{array}{l}\text { Fast } \\
\text { BACR15CE6D }\end{array}$ & 22380,9 & 32000 & 0,430 \\
\hline $\begin{array}{l}\text { Fast } \\
\text { BACR15BB6D }\end{array}$ & 1648,73 & 32000 & 18,409 \\
\hline $\begin{array}{l}\text { Fast } \\
\text { BAC30NW6 }\end{array}$ & 8948,34 & 124000 & 12,857 \\
\hline
\end{tabular}

Berdasarkan hasil analisis yang diperoleh pada nilai tegangan maksimum dari pembebanan internal pressure maupun beban tension pada kedua model dicantumkan pada tabel berikut.

Tabel 5. Nilai dan letak tegangan maksimum pada pembebanan internal pressure.

\begin{tabular}{|l|l|l|l|}
\hline $\begin{array}{l}\text { Assembly } \\
\text { Product } \\
\text { Repair Fuselage } \\
\text { Skin }\end{array}$ & $\begin{array}{l}\text { Tegangan } \\
\text { Maksimum } \\
\text { (Psi) }\end{array}$ & Letak & MS \\
\hline SRM Repair & 19268 & BACR15CE5D & 0,661 \\
\hline $\begin{array}{l}\text { Modifikasi SRM } \\
\text { Repair }\end{array}$ & 18265 & BACR15CE5D & 0,752 \\
\hline
\end{tabular}

Tabel 6. Nilai dan letak tegangan maksimum pada pembebanan tension.

\begin{tabular}{|l|c|c|c|}
\hline $\begin{array}{c}\text { Assembly } \\
\text { Product } \\
\text { Repair } \\
\text { Fuselage } \text { Skin }\end{array}$ & $\begin{array}{c}\text { Tegangan } \\
\text { Maksimum } \\
\text { (Psi) }\end{array}$ & Letak & MS \\
\hline SRM Repair & 23605,8 & BACR15CE6D & 0,356 \\
\hline $\begin{array}{l}\text { Modifikasi } \\
\text { SRM Repair }\end{array}$ & 22380,9 & BACR15CE6D & 0,430 \\
\hline
\end{tabular}

Dari kedua tabel diatas menunjukan bahwa nilai $M S$ untuk struktur $S R M$ repair lebih rendah dibandingkan struktur modifikasi SRM repair. Dilihat dari layout repair dan hasil analisis untuk pembebanan tension terlihat bahwa pada SRM repair menggunakan fastener sebanyak 110 dengan jarak spasi fastener 7,2D untuk diameter fastener 0,1875in mempunyai nilai $M S$ sebesar 0,356. Sedangkan struktur modifikasi SRM repair dilakukan pengurangan 1 baris fastener pada bagian atas dan bawah dengan jarak spasi fastener 5,4D dengan diameter yang sama mempunyai nilai MS0,430.

Dari perbandingan nilai tegangan dan margin of safety dapat dikatakan bahwa jarak spasi fastener juga ikut mempengaruhi kekuatan dari struktur fuselage skin repair. Untuk modifikasi SRM repair dalam kasus ini dinyatakan lebih aman dibandingkan SRM repair. 


\section{Kesimpulan}

1. Tegangan maksimum yang terjadi pada struktur SRM repair pada pembebanan internal pressure sebesar 19268 Psi, sedangkan pada pembebanan tension 23605,8Psi.

Untuk struktur modifikasi $S R M$ repair tegangan maksimumnya adalah 18265 Psi pada pembebanan internal pressure, sedangkan untuk pembebanan tension sebesar 22380,9Psi.

2. Berdasarkan nilai margin of safety struktur modifikasi SRM repair dinyatakan lebih aman dibandingkan struktur SRM repair, sehingga struktur tersebut bisa digunakan sebagai alternatif repair apabila repair scame untuk SRM repair tidak mungkin untuk dilakukan.

\section{Saran}

Saran yang bisa disampaikan pada penelitian ini adalah:

Walaupun dalam kasus ini dinyatakan bahwa modifikasi SRM repair lebih aman dibandingkan SRM repair, namun analisis masih sebatas pada analisis statis, sehingga masih perlu dilakukan pengembangan pengujian untuk mengetahui beban lelah (fatigue load), sehingga dapat diperkirakan umur lelah struktur repair tersebut.

\section{Ucapan Terima Kasih}

Atas terlaksananya penelitian ini penulis mengucapkan terima kasih kepada Sekolah Tinggi Teknologi Adisutjipto yang telah memberikan dukungan finansial serta fasilitasnya.

\section{DAFTAR PUSTAKA}

[1] Suyogkumar W. Balbudhe \&S. R. Zaveri, 2013, Stress Analysis Of Riveted Lap Joint, International Journal of Engineering Research \& Technology (IJERT), Volume 2 Issue 3Marc 2013.

[2] K. S. Bodadkar \& S. D. Khamankar, 2013, Stress Analysis Of Riveted Butt Joint, International Journal of Engineering Research \& Technology (IJERT), Vol. 2 Issue 8, August - 2013

[3] Michael C. Y. Niu, 1988, Airframe Structural Design, $2^{\text {nd }}$ Edition, Hongkong conmilit press LTD, Hongkong.

[4] Michael C. Y. Niu, 1997, Airframe Stress Analysis and Sizing, $2^{\text {nd }}$ Edition, Hongkong conmilit press LTD, Hongkong.

[5] MIL-HDBK-J.31 January 2003, Design Mechanical and Physical Properties.

[6] SRM (Structure Repair Manual) Boeing 747400 